\title{
Desenvolvimento embrionário tímico em fetos de gatos domésticos (Felis domesticus)
}

\author{
Camila Ercolini Barroso ${ }^{1 *}$ \\ Luana Célia Stunitz da Silva ${ }^{1}$ \\ Mariana Martinho \\ Fernanda Rodrigues Agreste ${ }^{1}$ \\ Pedro Primo Bombonato ${ }^{2}$ \\ ${ }^{1}$ PPG em Anatomia dos Animais Domésticos e Silvestres \\ ${ }^{2}$ Departamento de Cirurgia, Faculdade de Medicina Veterinária, Universidade de São Paulo \\ Av. Prof. Dr. Orlando Marques de Paiva, 87, CEP 05508 270, São Paulo - SP, Brasil \\ * Autor para correspondência \\ camilaercolini@usp.br
}

Submetido em 23/07/2011

Aceito para publicação em 16/04/2012

\section{Resumo}

Durante a vida fetal e no período neonatal o timo é um órgão de grande importância imunológica e, anatomicamente é o maior órgão linfático, com alta atividade linfopoiética, constando como precursor da linfopoiese. Estudos morfológicos sobre o desenvolvimento do timo são pouco esclarecedores e quando ocorrem englobam o assunto de forma genérica. Diante do exposto este estudo teve como objetivo caracterizar o desenvolvimento morfológico do timo de embriões e fetos de gatos domésticos (Felis domesticus), provenientes de gestação natural, utilizando as técnicas macroscópicas de dissecação e microscópica de luz. O timo dos gatos apresentou coloração rosa pálido e estava repousando na região do mediastino cranial, medialmente aos pulmões e dorsalmente à base do coração. Histologicamente apresentou duas regiões distintas, denominadas de cortical e de medular. Na região medular, foram evidenciadas células reticulares epiteliais com um núcleo grande e prolongamentos dendríticos. Os fetos apresentaram um desenvolvimento exponencial e mais acentuado a partir do $35^{\circ}$ dia de gestação.

Palavras-chave: Anatomia veterinária; Embriologia veterinária; Gatos; Timo

\section{Abstract}

Embryonic thymic development in fetuses of domestic cats (Felis domesticus). During fetal life, and during the neonatal period, the thymus is a very important immune organ, and is the largest lymphatic organ, which exhibits high lymphopoietic activity as a precursor of lymphopoiesis. Morphological studies on the development of the thymus are rare and only include general information. Given the above, this study aimed to characterize the morphological development of the thymus of embryos and fetuses of domestic cats (Felis domesticus), from natural pregnancy, using macroscopic dissection techniques and light microscopy. The thymus of the cats was pale pink and was resting in the region of the cranial mediastinum, medially to the lungs and dorsally to the base of the heart. Histologically, two distinct regions were observed (cortical and medullar). The medullary region had reticular epithelial cells with large nuclei and dendritic extensions. The fetuses had exponential growth and were more pronounced starting on the $35^{\text {th }}$ day of gestation.

Key words: Cats; Thymus; Veterinary anatomy; Veterinary embryology 


\section{Introdução}

O timo é um órgão linfoepitelial primariamente envolvido na diferenciação, seleção e maturação dos linfócitos $\mathrm{T}$, os quais por sua vez respondem a fenômenos como a rejeição de enxertos, hipersensibilidade retardada e reações de hospedeiro versus enxerto (ROSE, 1979; HAM; CORMACK, 1983; SUSTER; ROSAI, 1990; PICKER; SIEGELMAN, 1993). Discute-se sua participação no processo de maturação sexual e na hematopoiese, influenciando especificamente as linhagens grânulo e eritropoiéticas, e seus mecanismos de integração com o sistema nervoso e endócrino (REICHLIN, 1993; SAVINO; DARDENNE, 1995).

O timo rudimentar em mamíferos descende de sua localização cervical, na região faríngea, para uma posição final no mediastino cranial, em contato íntimo com o coração. Nos pássaros o timo permanece na região cervical e em peixes e anfíbios na faringe. Entretanto apesar das diferenças na localização entre espécies distintas, tanto o desenvolvimento subsequente e sua diferenciação celular são muito similares para todas as classes animais (RITTER; CRISPE, 1992).

Para o desenvolvimento, é necessária a migração e a proliferação das células da crista neural, que se origina de um grupo de células que migram ventrolateralmente da parte dorsal do tubo neural, para o interior da região faríngea. Essas células interagem, por contato ou através de secreções moleculares, com o epitélio do endoderma faríngeo induzindo assim a proliferação, migração e diferenciação da massa epitelial (GORDON et al., 2004).

Embora num primeiro momento estudos digam que o timo tenha derivado das células epiteliais de origem endodérmica e ectodérmica, recentes experimentos em aves e camundongos, via transplante ectópico, têm demonstrado conclusivamente que as células epiteliais tímicas são exclusivamente de origem endodérmica. Deste modo, refutam o modelo de "origem dual" de ontogenia epitelial tímica, até então preconizado, para o aceite de um novo modelo, o de "origem única" (ANDERSON; JENKINSON, 2001; BLACKBURN, MANLEY, 2004; BARTBLOTT et al., 2006).

Segundo Didio (2002), embriologicamente, este órgão é uma glândula par, porém, as faces mediais das suas primitivas estruturas direita e esquerda estão em contato íntimo, semelhante ao de um órgão ímpar bilobulado. Assim, as partes do timo são denominadas lobos direito e esquerdo, constituídos por lóbulos parciais ou totalmente envolvidos por cápsulas finas de tecido conjuntivo. O timo precoce dos fetos é uma estrutura lobular simples cercado por uma cápsula de tecido conjuntivo, sem septos ou vasos principais, estando composto inteiramente de células epiteliais (RITTER; CRISPE, 1992).

Macroscopicamente esta estrutura no gato doméstico recém-nascido é um órgão visivelmente lobular, de coloração rosa-pálida, que se estende cranialmente do manúbrio esternal, pela abertura torácica cranial, e ventralmente preenche dois terços do mediastino cranial (DASCHINGER, 1983). Em filhotes este órgão se estende cranialmente à região torácica, ventralmente à traqueia e caudalmente entre as veias braquiocefálica, entre quinta e sexta cartilagem intercostal, onde repousa na superfície ventral do pericárdio, situando-se dessa forma no mediastino cranial, com o lóbulo direito menor que o esquerdo (HUDSON; HAMILTON, 1993).

A morfologia do timo em gatos varia com a idade do animal, onde em neonatos ocorre o maior tamanho absoluto do órgão, para depois ocorrer a sua diminuição, e também varia individualmente, mesmo entre irmãos, e muitas vezes de forma considerável (DASCHINGER, 1983).

Segundo Silva et al. (2001), este órgão nos gatos detém a presença de duas porções, torácica e cervical, onde esta última, quando presente mostra-se fina e estreita, representando não mais que um quinto a um sexto do tecido tímico total, e pronuncia-se cranialmente ao primeiro par de costelas. A transição da porção torácica para a porção cervical é demarcada por sulcos que são sobrepostos lateralmente pelo parênquima da porção torácica. Nestes sulcos são encontradas a artéria e veia torácica interna direita e esquerda, ventralmente ao esterno (DASCHINGER, 1983).

A porção torácica direita é caracterizada como sendo uma porção menor e aproximadamente de formato triangular. Sua margem cranioventral convexa corre com a artéria torácica interna direita e sua margem caudal 
côncava encontra-se sobre a face cranial do coração. A veia cava cranial encontra-se dorsalmente a esta porção do timo e lateralmente ocorre a passagem do nervo frênico, bem como os lobos pulmonares direitos, os quais encobrem esta estrutura. Na superfície lateral da porção torácica esquerda mais dorsalmente e mais a esquerda localiza-se o nervo frênico. Caudalmente, após a borda dorsal livre, corre o nervo vago; mais à esquerda, medialmente ao nervo vago, encontra-se o tronco braquiocefálico e a artéria subclávia esquerda; e dorsolateralmente a região esquerda da porção torácica encontra-se encoberta pelo lobo cranial do pulmão esquerdo (DASCHINGER, 1983).

Após as duas porções torácicas craniais, surge a porção cervical que se inicia do terceiro par de costelas e avança em sentido cranial pela abertura torácica cranial, ventralmente à traqueia (DASCHINGER, 1983).

A porção cervical do timo se atrofia dentre os primeiros poucos meses de vida no cavalo, e, no entanto, não é comumente encontrada exceto no jovem potro. Ao contrário do observado em bovinos em que o timo é identificável, mesmo no adulto, como uma estrutura pálida e lobulada. Os lobos cervicais direito e esquerdo são bem desenvolvidos em bezerros. Assim como também é observado nos suínos que possuem o timo muito desenvolvido até a idade de abate, com aproximadamente seis meses (SMALLWOOD, 1992).

Quanto à sua irrigação esta apresenta características peculiares, visto que os capilares e os pequenos vasos destinados ao órgão não apresentam poros, mas sim uma membrana basal espessa, envolvida por uma camada de células epiteliais com prolongamentos finos que perfuram a lâmina basal e podem entrar em contato com as células reticulares epiteliais. Entretanto esta membrana basal não é totalmente contínua, atuando assim como uma barreira hematotímica no córtex, dificultando, embora não impedindo totalmente a passagem de antígenos ou macromoléculas do sangue para o interior do parênquima e, consequentemente, o seu contato com os linfócitos do órgão (JUNQUEIRA; CARNEIRO, 1999; SILVA et al., 2001).

Tratadistas clássicos como Martin (1902); Martin e Schuder (1938) e Ellenberger e Baum (1977) descrevem o suprimento sanguíneo do timo pelos ramos da artéria carótida comum, subclávia e torácica interna. Silva et al. (2001) observaram em gatos adultos SRD que a maior contribuição vascular se deu através dos ramos fornecidos pela artéria torácica interna esquerda e do tronco braquiocefálico. Santos et al. (1988), ao realizarem suas pesquisas com fetos de gatos, descreveram que nestes animais o órgão recebe ramos oriundos das artérias torácica interna direita e esquerda, subclávia esquerda e tronco braquiocefálico.

Este órgão linfoepitelial não possui vasos linfáticos aferentes e não constitui um filtro para a linfa, como ocorre nos linfonodos. Os poucos vasos linfáticos encontrados no mesmo são todos eferentes e localizamse nas paredes dos vasos sanguíneos e no tecido conjuntivo dos septos e da cápsula (KATO, 1997).

Encontra-se revestido por uma cápsula de tecido conjuntivo frouxo do qual partem septos de tecido semelhantes, subdividindo o órgão em lóbulos. Esses septos se estendem para a junção cortico-medular (BANKS, 1992). Histologicamente a cápsula e o septo do timo são constituídos de tecido conjuntivo areolar frouxo e tecido adiposo (GETTY, 1986; MELO, 1987). O parênquima de cada lóbulo está subdividido em lóbulos que variam em tamanho, dependendo da espécie, de 5 a $15 \mathrm{~mm}$ de largura. E o tecido intersticial do parênquima contém poucas fibras de tecido conjuntivo reticular, muito das quais podem estar concentradas ao redor dos vasos sanguíneos (GETTY, 1986).

O órgão é formado pelo córtex e pela medula bem definidos (BANKS, 1992). A parte mais externa de cada lóbulo, o córtex, é densamente infiltrada por linfócitos pequenos denominados timócitos. Os timócitos da medula não estão densamente agrupados como no córtex, caracterizando a medula como porção mais clara em um corte histológico (BANKS, 1992; TIZARD, 2002). Nesta região, é encontrada uma maior proporção de células epiteliais e poucos linfócitos, identificando-se células interdigitantes, importantes na apresentação de antígenos às células maturas (SUSTER; ROSAI, 1990).

Entre esses compartimentos evidencia-se uma região transicional, a chamada junção córtico-medular, caracterizada por um grande número de vasos, em 
geral arteríolas, circundadas por tecido conjuntivo perivascular, albergando linfócitos B e plasmócitos (SAINT-MARIE et al., 1986). Estudos ultraestruturais e imunocitoquímicos têm demonstrado a existência de subtipos de células epiteliais corticais e medulares, refletindo diferenças em relação à sua origem e função (VAN DE WIJNGAERT et al., 1984; VON GAUDECKER, 1991).

Aproximadamente 5\% das células linfóides tímicas residem na área subcapsular; apresentando principalmente células grandes, o que reflete a sua alta atividade mitótica. A maioria dos linfócitos (80-85\%) é encontrada no córtex e são de tamanho pequeno (menores do que as células T maduras), com células justapostas que não se dividem, dando a essa região do timo sua característica mais escura. Os outros $10 \%$ dos timócitos estão localizados na medula e são muito semelhantes aos linfócitos $\mathrm{T}$ em tamanho, fenótipo e maturidade funcional, representando o produto final do desenvolvimento intratímico (RITTER; CRISPE, 1992).

A população linfóide tímica imunofenotipicamente é heterogênea, caracterizando diferentes estágios de maturação na região cortical (DIJKSTRA; SMINIA, 1990; PICKER; SIEGELMAN, 1993; XAVIER, 1999). O acesso das células progenitoras ao timo de camundongos ocorre através de grandes vênulas medulares e da junção córtico-medular. Seguindo do córtex para a medula identifica-se um gradiente de diferenciação com células progressivamente de menores dimensões e com reduzida atividade mitótica (SUSTER; ROSAI, 1990). Os linfócitos medulares são os mais maduros, sendo possível a distinção entre linhagens auxiliares e supressoras (VAN EWIJK et al., 2000). Apenas uma pequena porcentagem dos linfócitos deixará o timo, via espaço perivascular ou sanguíneo (AMANO; HAMATANI, 1981).

A característica definitiva do órgão ocorre quando se observa a presença de corpúsculos tímicos denominados de corpúsculos de Hassal, os quais estão presentes na medula, tendo ainda sua função desconhecida, sendo observados com frequência nos estágios avançados de involução do timo (BANKS, 1992). Nota-se também a presença de macrófagos e de células dendríticas (também chamadas de células interdigitais) como população celular do estroma. Os macrófagos encontram-se espalhados pelo córtex e medula, podem aparecer cercados por uma proliferação de timócitos. Na medula tem-se a presença das células dendríticas as quais possuem origem hematopoiética na medula óssea (RITTER; CRISPE, 1992).

Diante do exposto, este estudo teve como objetivo caracterizar o desenvolvimento morfológico do timo de embriões e fetos de gatos domésticos (Felis domesticus), provenientes de gestação natural, utilizando as técnicas macroscópicas de dissecação e as técnicas microscópicas de luz.

\section{Material e Métodos}

Foram coletados 23 embriões, de idade gestacional estimada entre 15 e 22 dias e 39 fetos de felinos com idade gestacional estimada entre 35 a 50 dias. Todos procedentes de campanhas de castração promovidas por instituições conveniadas ao Centro de Controle de Zoonoses de São Paulo. (número da bioética 1676/2009)

Os períodos gestacionais foram estimados conforme metodologia preconizada por Evans e Sack (1973) e Knospe (2002). E com o auxílio de um paquímetro com divisões milimétricas foram realizadas as mensurações da distância occipto-sacral, tomando como referência a crista nucal e a última vértebra sacral (Crow-Rump).

Após a abertura dos úteros gravídicos tanto os embriões quanto os fetos foram identificados, mensurados e fotografados. Os embriões foram embebidos em solução de formol tamponado $10 \%$. Os fetos foram dissecados para a coleta do timo e posteriormente fixados em solução de formol tamponado $10 \%$.

Os embriões, após a fixação em solução de formaldeído tamponado $10 \%$, por pelo menos $24 \mathrm{~h}$, foram tratados em álcool 70\% overnight. Desidratados em etanol 95\% por 30min e em uma série composta por três partes de etanol absoluto, sendo a primeira por 30 min e a segunda e terceira por $1 \mathrm{~h}$. Diafanizados em xilol I e II por 20min cada e xilol III por $1 \mathrm{~h}$. Incluídos em uma sequência de Paraplast ${ }^{\circledR}$ à $60^{\circ} \mathrm{C}$ composta por três partes, de $1 \mathrm{~h}$ cada. Procedendo-se com o emblocamento 
dos embriões inteiros e em cortes sequenciais de $5 \mu \mathrm{m}$ de espessura em micrótomo (Leica RM 2065) para a obtenção das lâminas. Estas foram desparafinizadas em estufa a $60^{\circ} \mathrm{C}$ por $2 \mathrm{~h}$. Coradas com Hematoxilina-Eosina (HE) e Tricrômio de Masson. Fotomicrografadas em Microscópio Olympus BX 60 acoplado a câmera Axio CAM HRc, utilizando-se o software Zeiss ${ }^{\circledR}$ KS 400.

Nos fetos após a ressecção do membro torácico esquerdo e da musculatura torácica foram removidas a $2^{\mathrm{a}}, 3^{\mathrm{a}}$, e $4^{\mathrm{a}}$ costelas do antímero esquerdo, evidenciando assim o lobo torácico tímico esquerdo Os timos dos fetos após permanecerem no fixador de solução de formaldeído tamponado $10 \%$ por pelo menos $12 \mathrm{~h}$ foram lavados em água destilada e desidratados em etanol $90 \%$ por $1 \mathrm{~h}$. Em seguida, foram submetidos a uma sequência de três partes, de 1h30min cada, em etanol absoluto. Diafanizados em xilol I e II por 1h30min cada, incluídos em uma série de três partes de Paraplast ${ }^{\circledR}$ à $60^{\circ} \mathrm{C}$, por $2 \mathrm{~h}$ cada e seu emblocamento. Preparação das lâminas e coradas com Hematoxilina-Eosina (HE) e Tricrômio de Masson e fotomicrografadas.

\section{Resultados}

Aos 15 dias de gestação, foi observada, nos embriões coletados, a presença de células que formaram o parênquima, mas sem haverem realizado a migração que dará início ao desenvolvimento do timo. Já aos 22 dias foi possível diferenciar histologicamente o timo nos embriões, podendo ser observado a existências das células migratórias precursoras dos timócitos em região faringeana.

Nos fetos de 28 dias, ocorreu uma diferenciação progressiva do timo e por volta dos 35 dias gestacionais foi possível visualizar o início da lobulação tímica, sendo também observada uma grande quantidade de tecido conjuntivo interlobular. Juntamente a esse tecido notou-se uma grande quantidade de capilares irrigando a região, bem como a presença de vasos sanguíneos (Figura 1-A) e diversas ramificações que adentravam aos lobos juntamente com os septos. Contudo, nesse período gestacional, ainda não se pôde observar a diferenciação do parênquima quanto à região medular ou cortical nem tão pouco os tipos celulares característicos (Figura 1-A e 2-A).

Aos 45 dias o feto apresentou o timo organizado em lobos (Figura 2-B) revestido por uma cápsula de tecido conjuntivo fibroso, o qual possuí invaginações para a formação de septos que dividiam parcialmente o lobo, formando então a estrutura lobular.

A cortical como a porção mais externa dos lóbulos e com coloração mais escura devido à alta concentração de linfócitos T em inicio de maturação. E a zona medular, parte mais interna do lóbulo, composta por linfócitos T em estágio mais avançado de maturação e por uma grande quantidade de células reticulares epiteliais (Figura 1-B), o que confere uma coloração mais clara a esta porção do órgão.

Os timos dos fetos coletados apresentaram coloração rosa-pálido, posicionados na região de mediastino cranial, medialmente aos pulmões e dorsalmente à base do coração. A porção cranial ora apresentava discreta divisão entre lobo esquerdo e direito, ou estava unido como uma massa única. E sua porção caudal se apresentou com divisão acentuada entre lobo esquerdo e direito, e também foi observada unida como uma massa única, assim como observado na porção cranial. Estas características foram encontradas em indivíduos irmãos de aproximadamente 35 dias.

O timo estava localizado em região de $1^{\text {a }}$ a $5^{\text {a }}$ costela, relacionando-se caudalmente com a aurícula direita do coração, dorsalmente com o esôfago torácico, lateralmente com a região de incisura tímica entre os lobos cervicais e torácicos, ventralmente e medialmente com o lobo cranial do pulmão esquerdo. Apresentando dimensões maiores quando comparado ao lobo direito. 
FIGURA 1: Fotomicrografias de timos de fetos de gatos domésticos (Felis domesticus) corados com Hematoxilina/eosina. A - Aos 35 dias de gestação evidencia-se a grande presença de tecido conjuntivo interlobular e timócitos de diferentes estágios de maturação nos lóbulos. As setas amarelas apontam os capilares (40x). B - Aos 45 dias de gestação identifica-se a zona cortical, à direita, de coloração mais escura, e a zona medular, de coloração mais clara (40x). C - Aos 50 dias de gestação nota-se a presença dos Corpúsculos tímicos (seta amarela) (40X).

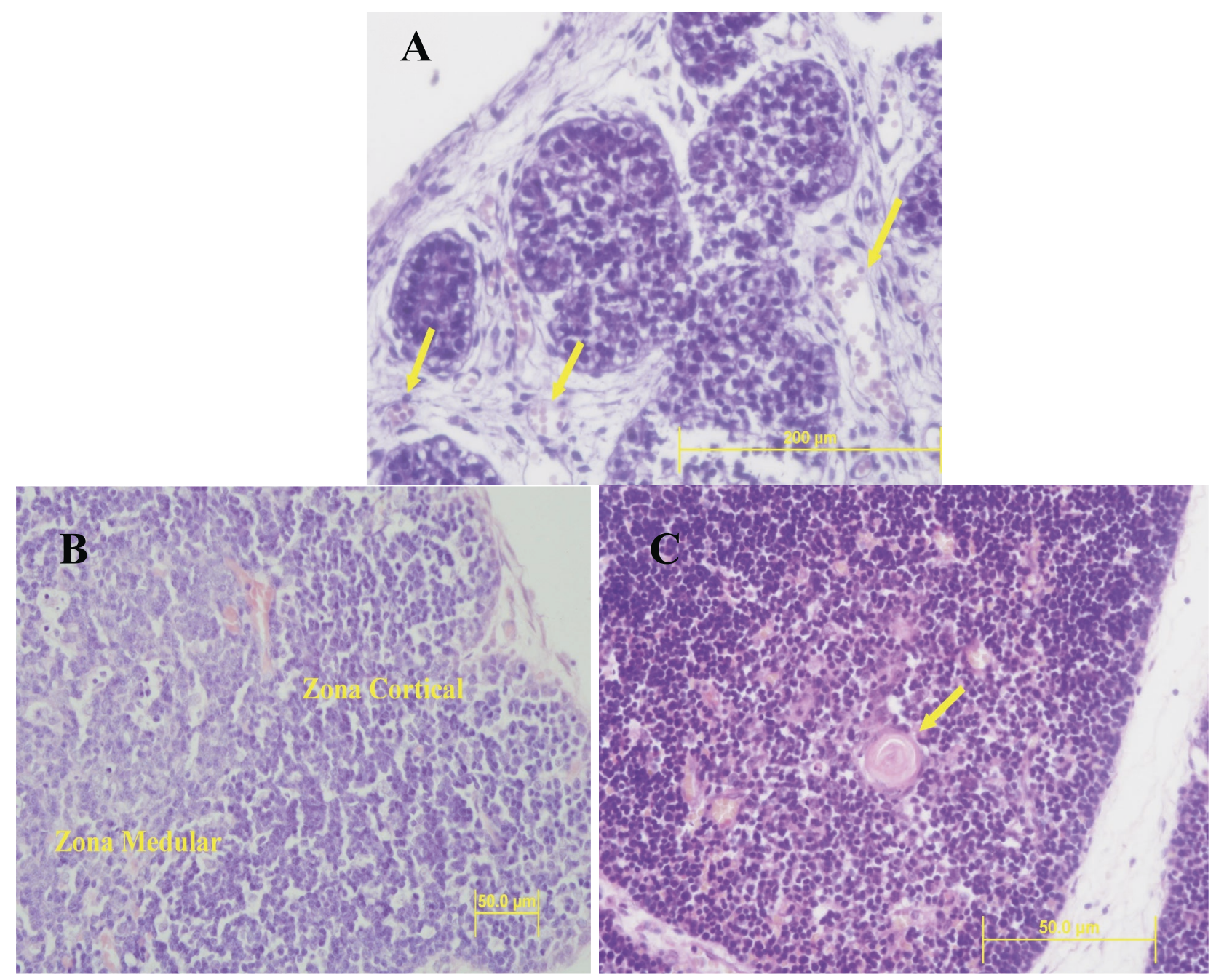

A porção tímica torácica direita relacionava-se caudalmente com o coração e medial e ventralmente ao lobo cranial pulmonar direito.

Observaram-se sulcos em região de transição entre os lobos torácicos para os lobos cervicais, dividindo estes lobos, e com a presença da confluência da artéria e veia torácica interna.

Na porção cervical do timo foi observada uma posição ventral em relação à traqueia em seu terço distal, macroscopicamente fina e estreita.
A análise microscópica permitiu a observação das células reticulares epiteliais, as quais se apresentaram em ambas as zonas do timo, porém apareceram com maior frequência por volta dos 50 dias na porção medular do lóbulo. Morfologicamente apresentavam com um núcleo grande e com extensões dendríticas. 
FIGURA 2: Fotomicrografias de timos de fetos de gatos domésticos (Felis domesticus) corados com Tricrômio de Masson. A - Aos 35 dias evidenciam-se os lóbulos precários (L), ainda em formação, sem diferenciação entre região medular e cortical, a seta indica a cápsula do timo (40x.). B - Aos 45 dias nota-se o parênquima organizado, a seta indica a cápsula tímica (4x). C Aos 45 dias. Nota-se uma veia (Veia na figura) de grande calibre envolta pelo tecido conjuntivo denso, que adentrando ao lóbulo é denominado de septo interlobular indicado pela seta (40x). D - Aos 45 dias observa-se a região de transição entre a zona cortical, lado superior e direito (escura), e a zona medular, lado inferior e esquerdo (clara). As setas mostram células reticulares epiteliais da medular (100x).
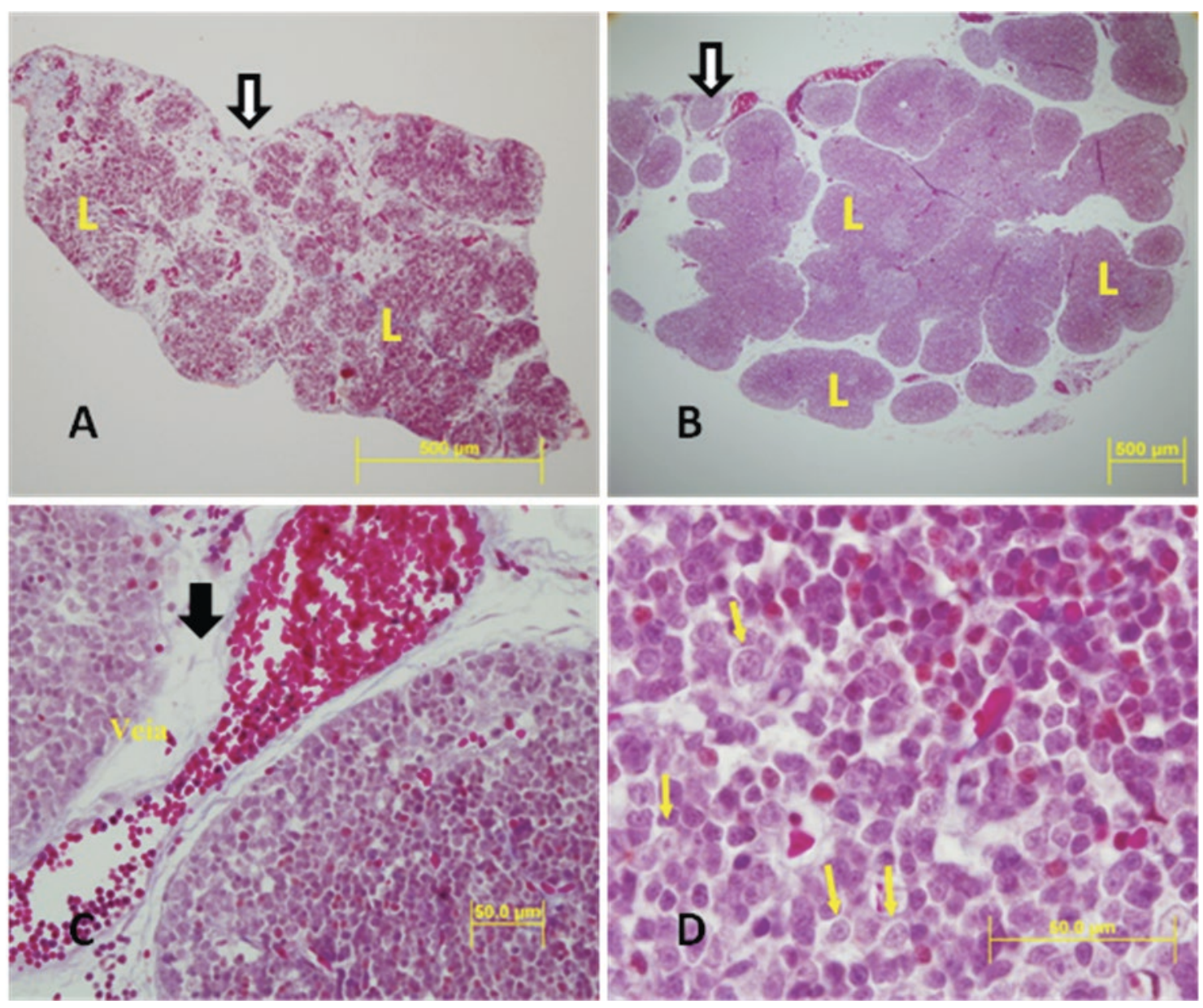

As artérias penetravam no timo pela cápsula, ramificavam-se e aprofundavam-se seguindo os septos conjuntivos (Figura 2-C), onde originavam arteríolas que penetravam no parênquima, seguindo os limites entre a cortical e a medular. Já estas arteríolas formavam capilares que penetravam na cortical, ramificavamse e se anastomosavam em direção a medular, onde desembocavam em vênulas.

Os capilares do timo possuíam endotélio sem poros e com uma lâmina basal muito espessa As células endoteliais se apresentaram com prolongamentos finos

que perfuravam a lamina basal e entravam em contato com as células reticulares epiteliais. Tais células envolviam externamente os capilares contribuindo assim para a formação da barreira hematotímica, que só existe na cortical.

Os chamados Corpúsculos tímicos, a estrutura mais característica presente no timo, composta por células reticulares epiteliais em arranjos concêntricos localizadas na zona medular do órgão, sendo tais estruturas observadas apenas a partir dos 50 dias de gestação (Figura1-C). 


\section{Discussão}

Quanto aos achados macroscópicos do timo nos felinos, foi observado que tal órgão possui coloração róseo-pálida, com aspecto visivelmente lobular e com a presença de duas porções, a torácica e a cervical, estes achados foram semelhantes aos relatados por Daschinger (1983) e Silva et al. (2001) em gatos domésticos SRD.

A localização do órgão foi observada na região do mediastino cranial ao coração e ventral a traqueia e a sua forma variou individualmente entre fetos da mesma ninhada, assim como descrito por Daschinger (1983), em gatos domésticos SRD, e Bombonato et al. (2001), em fetos de caprinos da raça Saanen. O lobo direito detinha menores dimensões do que o esquerdo, corroborando assim com os relatos de Hudson e Hamilton (1993), em gatos.

Com relação à forma e tamanho do timo observouse variabilidade, por não apresentarem padronização, corroborando com Daschinger (1983), Santana et al. (2007) e Lima (2009).

Quanto à sintopia, os achados ora visualizados neste estudo foram semelhantes aos de Daschinger (1983), em que o nervo vago estava localizado dorsalmente à porção torácica havendo também a presença de sulcos na transição entre os lobos torácicos para os lobos cervicais. Ademais tanto a artéria quanto a veia torácica interna confluíam nestes sulcos existentes.

Segundo Kato (1997) e Junqueira e Carneiro (1999), durante o desenvolvimento do timo alguns ramos vasculares penetram no interior do parênquima acompanhando o tecido conjuntivo, para a formação de um espaço de tecido conjuntivo perivascular, fato este que foi observado no presente trabalho. As arteríolas existentes se ramificavam e se aprofundavam seguindo os septos conjuntivos, formando então capilares que penetravam na cortical e depois se dirigiam para a região medular, onde desembocavam em vênulas. As quais confluíam para formar as veias que penetravam nos septos conjuntivos e saiam do timo pela cápsula.

No tocante ao suprimento sanguíneo do timo dos fetos de gato observou-se que o órgão era irrigado pela artéria torácica interna, assim como também relatado por Daschinger (1983). Entretanto segundo Silva et al. (2001) a maior contribuição vascular para o timo de gatos ocorre através de ramos fornecidos pela artéria torácica interna esquerda e pelo tronco braquicefálico.

Como relatado por Dijkstra e Sminia (1990), Suster e Rosai (1990), Picker e Siegelman (1993), Xavier (1999) e Van Ewijk et al. (2000) foi observado um conjunto de células tais como, reticulares epiteliais, endoteliais e timócitos com morfologias distintas e de tamanhos díspares, proporcionando um microambiente heterogêneo em um órgão normal.

Quanto à histologia do órgão é observada a existência de uma cápsula e de septos no timo, estes consistindo de tecido conjuntivo frouxo e tecido adiposo, corroborando desta maneira com Melo (1987) e Banks (1992). Os corpúsculos tímicos foram encontrados preferencialmente na zona medular, nos fetos de 50 dias de gestação, tendo as células epiteliais dispostas de forma concêntrica, assim como relatado tanto por Getty (1986) quanto por Banks (1992). E as células reticulares epiteliais foram observadas em ambas as zonas do timo, porém apareceram com maior frequência na porção medular do lóbulo. Morfologicamente possuíam um grande núcleo e diversas extensões dendríticas assim como as afirmações de Suster e Rossai (1990) que descrevem a morfologia normal do timo em humanos.

O conhecimento do comportamento vascular, da estrutura e das interferências que ocorrem no desenvolvimento e na involução do timo poderá esclarecer diversas questões ainda não caracterizadas adequadamente, como as doenças auto-imunes, os tumores tímicos, a persistência tímica e tantas outras ligadas ao comprometimento imunitário, auxiliando assim na melhor fundamentação das diferentes propostas para a explicação da involução fisiológica que o timo sofre nos mamíferos.

\section{Referências}

AMANO, M.; HAMATANI, K. The short-lived lymphocyte in the thymus cortex of the rat. Cell Structure and Function, Kyoto, v. 6, p. 159-166, 1981.

ANDERSON, G.; JENKINSON, E. J. Lymphostromal interactions in thymic development and function. Nature Reviews Immunology, London, v. 1, p. 31-40, 2001. 
BANKS, J. W. Histologia veterinária aplicada. 2. ed. São Paulo: Editora Manole. 1992. 560 p.

BARTBLOTT, T.; KELLER, M. P.; KRENGER, W.; HOLLÄNDER, G. A. A short primer on early molecular and cellular events in thymus organogenesis and replacement. Swiss Medical Weekly, Basel, v. 136, p. 365-369, 2006.

BLACKBURN, C. C.; MANLEY, N. R. Developing a new paradigm for thymus organogenesis. Nature Reviews Immunology, London v. 4, p. 278-289, 2004.

BOMBONATO, P. P.; SANTANA, M. I. S.; SILVA, F. O. C.; SEVERINO, R. S.; DRUMMOND, S. S. Irrigação do timo de fetos caprinos da raça Saanen: estudo comparativo. Brazilian Journal of Veterinary Research and Animal Science, São Paulo, v. 38, p. 203 208, 2001

DASCHINGER, V. E. K. Zur topographie und blutgefäßversorgung des thymus der neugeborenen hauskatze (Felis silvestris f. catus). Zeitschrift fur Versuchs Tierkunde, Jena, v. 25, p. 100-113, 1983.

DIDIO, J. A. Sistema endócrino. In: DIDIO, J. A. (Ed.). Tratado de anatomia sistêmica aplicada. v. 2. 2. ed. São Paulo: Atheneu, 2002 p. 583-603.

DIJKSTRA, C. D.; SMINIA, T. Thymus: normal anatomy, histology, immunohistology, ultraestructure, rat. In: JONES, T. C.; WARD, J. M.; MOHR, U.; HUNT, R. D. (Ed.). Hemopoietic system. Berlin: Springer-Verlag, 1990. p. 185-193.

ELLENBERGER, W.; BAUM, H. Hudbuch der vergleichenden anatomie der haustiere. 18. ed. Berlin: Springer Verlag, 1977. p. 603.

EVANS, H. E.; SACK, W. O. Prenatal development of domestic and laboratory animals. Anatomia, Histologia, Embryologia, Berlin, v. 2, p. 11-45, 1973.

GETTY, R. Sisson/Grossman anatomia dos animais domésticos. Vol. 2. 5 ed. Rio de Janeiro: Guanabara Koogan, 1986. 2000 p.

GORDON, J.; WILSON, V. A.; BLAIR, N. F.; SHERIDAN, J.; FARLEY, A.; WILSON, L.; MANLEY, N.; BLACKBURN, C. C. Functional evidence for a single endodermal origin for the thymic epithelium. Nature Immunology, New York, v. 5, p. 546-553, 2004. HAM, A. W.; CORMACK, D. H. Histologia. Rio de Janeiro: Guanabara Koogan, 1983. 907 p.

HUDSON, L. C.; HAMILTON, W. P. Atlas of feline anatomy for veterinarians. Philadelphia: W. B. Saunders Company, 1993. 287 p.

JUNQUEIRA, L. C.; CARNEIRO, J. Histologia básica. 9 ed. Rio de Janeiro: Guanabara Koogan, 1999. 488 p.

KATO, S. Thymic microvascular system. Microscopy Research and Technique, Malden, v. 38, n. 3, p. 287-299, 1997.

KNOPSE, C. Periods and stages of the prenatal development of the domestic cat. Anatomia, Histologia, Embryologia, Berlin, v. 31, p. 37-51, 2001

LIMA, E. M. M.; BRAVO, M. O.; VIANNA, A. R. C. B.; SILVA, F. O. C.; SEVERINO, R. S.; DRUMMOND, S. S.; SANTANA, M. I. S. Suprimento vascular arterial do timo em aves (Gallus gallus domesticus) da linhagem Master Gris Cou Plumé. Biotemas, Florianópolis, v. 22, n. 3, p. 171-176, 2009.

MARTIN, P. Lehrbuch der anatomie der hausdtiere. Stuttgart, Velag von Schickhardt und Ebner, Berlin, v. 1, p. 430, 1902.

MARTIN, P.; SCHUDER, N. Lehrbuch der anatomie der hausdtiere. Stuttgart, Velag von Schickhardt und Ebner, Berlin, v. 3, p. 370, 1938.
MELO, A. M. A. Alguns aspectos da estrutura e funções do timo em Gallus domesticus. Repositório de Trabalhos do Laboratório Nacional de Investigação Veterinária, Porto, v. 19, p. 11-24, 1987. PICKER, L. J.; SIEGELMAN, M. H. Lymphoid tissues and organs. In: PAUL, W. E. (Ed.). Fundamental immunology. 3. ed. New York: Raven Press, 1993. p. 145-197.

REICHLIN, S. Neuroendocrine-immune interactions. The New England Journal of Medicine, Waltham, v. 329, p. 1246-1253, 1993.

RITTER, M. A.; CRISPE, I. N. The thymus. New York: Oxford University Press, 1992. 85 p.

ROSE, M. E. The immune system in birds. Journal of the Royal Society Medicine, London, v. 72, n. 9, p. 701-705, 1979.

SAINT-MARIE, G.; PENG, F. S.; MARCOUX, D. The stroma of the thymus of the rat: morphology and antigen diffusion, a reconsideration. The American Journal of Anatomy, New York, v. 177, p. 333-352, 1986

SANTOS, A. L. Q.; SILVA, F. O. C.; SEVERINO, R. S.; DRUMMOND, S. S.; BOMBONATO, P. P. Contribuição ao estudo da vascularização arterial do timo em gatos SRD. In: CONGRESSO BRASILEIRO DE ANATOMIA DA UNIVERSIDADE DE BRASÍLIA, XV, 1988, Brasília. Anais... Brasília: Universidade de Brasília, 1988. p. 109.

SAVINO, W.; DARDENNE, M. Immune-neuroendocrine interactions. Immunology Today, Ohio, v. 16, n. 7, p. 318-322, 1995. SILVA, F. O. C.; BOMBONATO, P. P.; SEVERINO, R. S.; SANTOS, A. L. Q.; DRUMMOND, A. S.; SANTOS, A. L. Q.; BORGES, M.; COSTA, C. Suprimento arterial do timo em cães SRD, Brazilian Journal of Veterinary Research and Animal Science, São Paulo, v. 31, n. 2, p. 89-94, 1994.

SILVA, F. O. C.; SEVERINO, R. S.; SANTOS, A. L. Q.; DRUMMOND, A. S.; SILVA; M. BOMBONATO; P. P. REZENDE; R. J. LIMA; E. M. M. Suprimento arterial do timo em gatos sem raça definida. Bioscience Journal, Uberlândia, v. 17, n. 1, p. 61-66, 2001.

SMALLWOOD, J. E. A guided tour of veterinary anatomy. Philadelphia: W. B. Saunders, 1992.390 p.

SUSTER, S.; ROSAI, J. Histology of the normal thymus. The American Journal of Surgical Pathology, Charlottesville, v. 14, p. 284-303, 1990

TIZARD, I. R. Imunologia veterinária: uma introdução. 6. ed. São Paulo: Editora Roca, 2002. 548 p.

VAN DE WIJNGAERT, F. P.; KENDALL, M. D.; SCHUURMAN, H. J.; RADEMAKERS, L. H.; KATER, L. Heterogeneity of epithelial cells in the human thymus. An ultrastructural study. Cell \& Tissue Research, Freiburg, v. 237, n. 2 p. 227-237, 1984.

VAN EWIJK, W.; HOLLÄNDER, G.; TERHORST, C.; WANG, B. Stepwise development of thymic microenvironments in vivo is regulated by thymocyte subsets. Development, Cambridge, n. 127, p. $1583-1591,2000$.

VON GAUDECKER, B. Functional histology of the human thymus. Anatomia, Histologia, Embriologia, Berlin, v. 183, p. 1-15, 1991.

XAVIER, J. G. Repercussões estruturais da desnutrição protéica e renutrição em tecidos linfo-hematopoiéticos de camundongos. 1999. 254 f. Tese (Doutorado em Patologia Experimental e Comparada) - Universidade de São Paulo, São Paulo. 1999. 